\title{
Approaches to landscape- and seascape-scale conservation planning: convergence, contrasts and challenges
}

\author{
Rob ERT L. PresSEY and MADELEINE C. BotTRILL
}

\begin{abstract}
Non-government organizations (NGOs), agencies and research groups around the world have developed diverse approaches to conservation planning at the scale of landscapes and seascapes. This diversity partly reflects healthy differences in objectives, backgrounds of planners, and assumptions about data and conservation priorities. Diversity also has disadvantages, including confusion among donors and prospective conservation planners about what to fund and how to plan. To help reduce this confusion, we compared approaches described in separate articles by four major conservation NGOs. We structured our comparison with an 11-stage framework for conservation planning. We found considerable agreement between approaches in their recognition and ways of addressing many planning stages. The approaches diverged most obviously in ways of collecting socio-economic and biodiversity data and identifying explicit conservation objectives. Even here, however, the approaches tend to be complementary and there is potential to combine them in many landscapes and seascapes. Our review emphasizes that systematic methods are having real benefits in guiding effective conservation investments. We finish by outlining two challenges for conservation planning generally: (1) managing the transition from planning to applying conservation actions, and (2) assessing the costs and benefits of conservation planning.
\end{abstract}

Keywords Biodiversity, conservation planning, costs, data, guidelines, implementation, stakeholders, threats

\section{Introduction}

Onservation planning is the process of deciding where, $\checkmark$ when and how to allocate limited conservation resources to minimize the loss of biodiversity, ecosystem services and other valued aspects of the natural world. Systematic methods (Margules \& Pressey, 2000) have been developed over the last 25 years to increase the effectiveness

Robert L. Pressey (Corresponding author) Australian Research Council Centre of Excellence for Coral Reef Studies, James Cook University, Townsville, QLD 4811, Australia. E-mail bob.pressey@jcu.edu.au

Madeleine C. Bottrill The University of Queensland, Brisbane, Australia.

Received 9 March 2009. Revision requested 14 April 2009.

Accepted 19 May 2009. of conservation planning. Applications of systematic conservation planning vary in extent from global (Rodrigues et al., 2004) to the size of individual conservation areas (Lombard et al., 2001).

Although landscapes and seascapes have no fixed size and vary widely in extent there are three characteristics that help to define the nature of their boundaries and constrain their upper and lower extents. Firstly, their boundaries can demarcate common patterns and processes of biodiversity and human uses, governance and threats, presenting planners with a manageable number of objectives, constraints and opportunities. Secondly, landscapes and seascapes are large enough to provide spatial context for conservation decisions, considering complementarity (Vane-Wright et al., 1991) and connectivity (Calabrese \& Fagan, 2004) between areas, threats to natural features, and relationships between different human uses (Groves et al., 2002). Thirdly, landscapes and seascapes are sufficiently small that there is a more or less direct connection between the areas selected from maps as candidates for conservation and the areas in which conservation actions are eventually applied (Morrison et al., 2009).

Conservation planning continues to evolve, with contributions from research institutions, agencies and nongovernment organizations (NGOs). Some co-evolution of approaches is supported by exchanges of individuals, collaborations and scientific literature. At a broad level two main goals, representation and persistence of biodiversity (Margules \& Pressey, 2000), are shared, but approaches to planning at the scale of landscapes and seascapes remain diverse. This reflects different specific objectives (Redford et al., 2003), different circumstances in which the objectives are to be achieved, different backgrounds and training of people in planning teams, and healthy disagreement over assumptions about the most appropriate data (e.g. Brooks et al., 2004, and subsequent replies) and methods for identifying potential conservation areas.

For many people this diversity of approaches presents a bewildering array of alternatives. There is increasing uncertainty in the conservation science community, among people new to conservation planning, and among governments and donors about how to choose between apparently competing approaches. Uncertainty is increased by the sometimes assertive and exclusive promotion of approaches. Diversity and competition also have other disadvantages. They impede cooperation between organizations 
and individuals, limit the effectiveness of conservation planning by failing to identify complementarities between approaches and alternative solutions to problems, and send conflicting messages to partners, donors and other stakeholders.

Making sense of this diversity requires differences between approaches to be explained, and some comparisons are available. Johnson (1995) related differences between landscape-scale approaches to underlying values and objectives. Redford et al. (2003) illustrated differences between approaches in terms of objectives, targeted biodiversity features (e.g. species, vegetation types, ecological processes) and spatial scales. Gordon et al. (2005) briefly summarized six approaches, selecting two for comparison according to a list of key characteristics. Bottrill et al. (2006) compared sets of biodiversity features selected by five NGOs in the same landscape, revealing both overlaps and differences, the latter reflecting divergent objectives and rationales. There appear to be no published spatial comparisons of areas identified by different approaches within the same regions. This leaves unanswered questions about differences in the extent, configuration, coverage of biodiversity patterns and processes, and socio-economic implications of recommended conservation areas. Taken together, these previous comparisons are useful for experienced planners to validate and refine their own approaches by combining elements from others, as suggested by Johnson (1995).

\section{Approaches to conservation planning}

Four articles in this issue of Oryx provide a further contribution to understanding different approaches to conservation planning, assembling descriptions by four international NGOs of approaches at the scale of landscapes and seascapes (African Wildlife Foundation, AWF: Henson et al., 2009; The Nature Conservancy, TNC: Green et al., 2009; Wildlife Conservation Society, WCS: Didier et al., 2009; World Wildlife Fund, WWF: Morrison et al., 2009). Each NGO describes case studies (Fig. 1), focusing on aspects of spatial analysis.

During the last 10 years each of these NGOs was a partner in, and received financial support from, the Global Conservation Program (GCP) of the United States Agency for International Development. Two other NGOs were also partners in GCP: Conservation International and Enterprise Works/Vitae. Conservation International has its own planning approaches for landscapes and seascapes: Key Biodiversity Areas (Langhammer et al., 2007) and Conservation Corridors. The GCP programme was designed to encourage each partner to develop and test threats-based approaches to conservation planning at the scale of landscapes and seascapes.

The four articles and this introduction complement previous comparisons of approaches in three ways. Firstly, planners from the NGOs present accessible summaries of what they do and why, discussing lessons learnt and unresolved problems. This goes beyond scientific interest

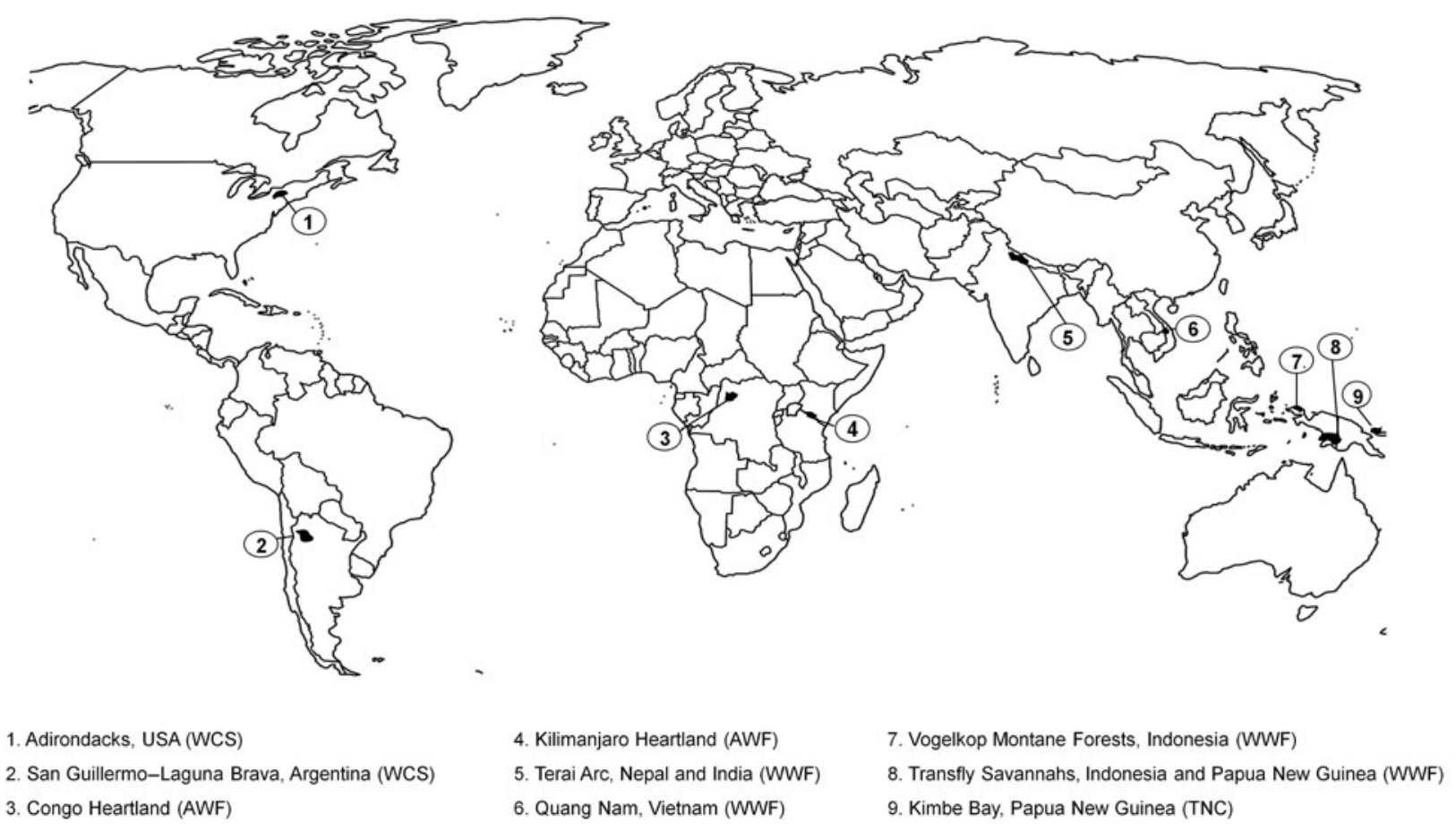

FIG. 1 Landscapes and seascapes featured as case studies by Didier et al. (2009, WCS), Green et al. (2009, TNC), Henson et al. (2009, AWF) and Morrison et al. (2009, WWF). 
to practical implications. The NGOs are strongly connected to legislators, policy-makers and agencies, they spend considerable resources on planning and implementation, and they increasingly influence the persistence of biodiversity and people's livelihoods. Secondly, the articles describe recent applications of approaches that have been adapted to their particular study areas and refined since they were previously characterized and compared. Thirdly, we place the four approaches in the context of a new framework for conservation planning. This framework forms the main structure of our forthcoming IUCN guidelines (sponsored by IUCN's Species Survival Commission and World Commission on Protected Areas), intended to provide guidance for construction of planning approaches.

The guidelines incorporate all current approaches, illustrating how they differ and where they overlap, with a structure provided by 11 stages (Fig. 2, Table 1) that have evolved from earlier descriptions of conservation planning (Margules \& Pressey, 2000; Cowling \& Pressey, 2003). These stages indicate approximately the order in which decisions and tasks would be addressed by planning teams. In the guidelines and here we refer to conservation areas as places where some kind of conservation action is applied. These actions could include reservation, regulation of extractive uses, control of invasive species, restoration, management of water flows, and others.

Here we contribute summaries of how AWF, TNC, WCS and WWF have addressed stages of the planning process, observations of the similarities and differences between the approaches, comments on strengths and innovations, and an outline of two important issues that have not been adequately addressed by systematic conservation planning generally. This is also an opportunity to emphasize the extent to which systematic methods are having real benefits in guiding effective conservation investments in diverse regions.

\section{Convergence and contrasts}

We use our 11-stage framework to organize observations on areas of strength and innovation of the four NGO approaches as well as areas of convergence and contrast (Tables 2-3). There are some explicit overlaps. AWF's Heartland Conservation Process has been shaped through collaboration with TNC and has similarities to WCS's Landscape Species Approach (Henson et al., 2009). The application of the Landscape Species Approach in the Adirondacks (Fig. 1) has led to collaboration between the WCS and TNC in this

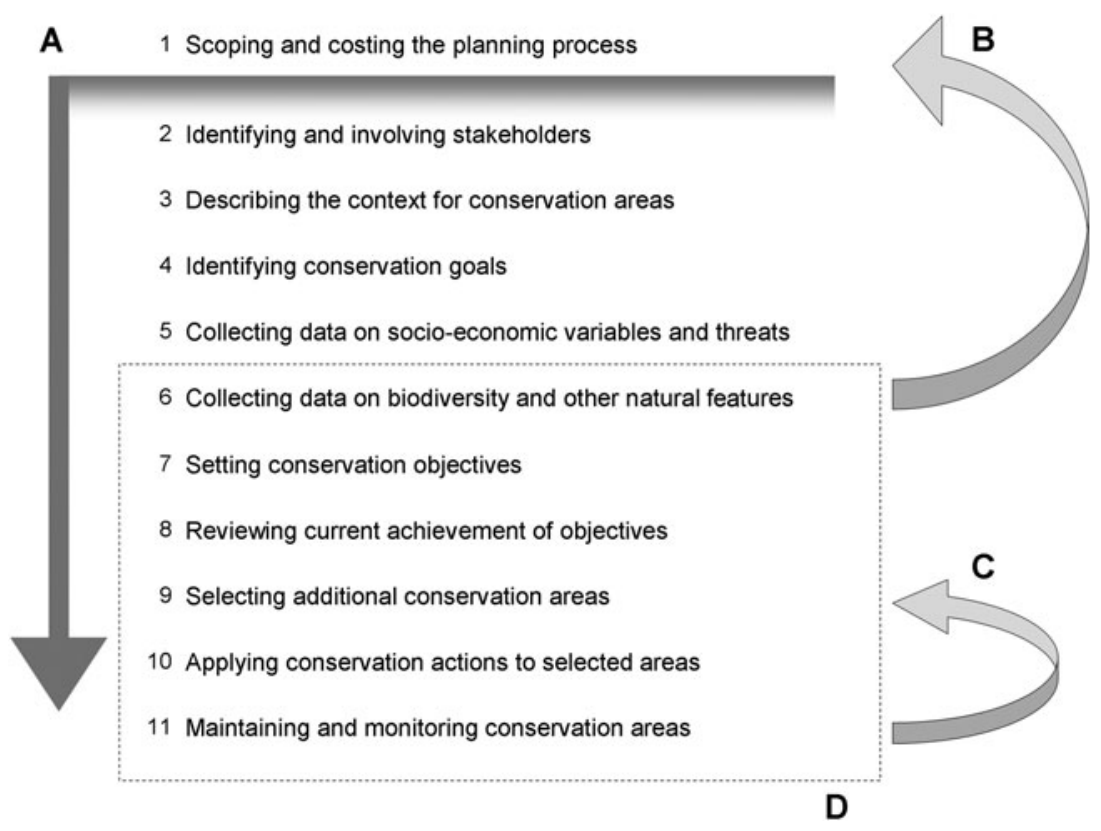

FIG. 2 Diagrammatic representation of the process of conservation planning as 11 main stages. We have depicted the planning process as a linear sequence but, in practice, some stages will be undertaken simultaneously and there will be many feedbacks from later to earlier stages. From the time that stakeholders are first involved, for example, they will contribute in different ways throughout the process (A). Among the reasons for feedbacks are possible revisions of the boundaries of the planning region when biodiversity data are collected (B). Another involves lessons for planning decisions (Stage 9) from maintenance (Stage 11) that indicate ways of locating and configuring conservation areas to minimize subsequent liabilities for management (C). Recent enlargement of the framework is illustrated by the addition of stages to those described by Margules \& Pressey (2000), enclosed by the dashed rectangle (D). Notably, the newer stages are mainly concerned with the social, economic and political context for the more technical stages that follow. Alternative depictions of the planning framework are, of course, possible (Knight et al., 2006; Conservation Measures Partnership, 2007; Moilanen, 2008), depending on which parts of the process and interrelationships are being emphasized. 
TABle 1 Description of our 11 main stages of conservation planning (Fig. 1).

\begin{tabular}{|c|c|}
\hline Stage & Description \\
\hline $\begin{array}{l}\text { 1, Scoping \& costing the planning } \\
\text { process }\end{array}$ & $\begin{array}{l}\text { Decisions are necessary on the boundaries of the planning region, the composition } \& \\
\text { required skills of the planning team, the available budget, necessary funds in addition } \\
\text { to those available \& how each step in the process will be addressed, if at all }\end{array}$ \\
\hline 2, Identifying \& involving stakeholders & $\begin{array}{l}\text { Important stakeholders include those who will influence or be affected by conservation } \\
\text { actions arising from the planning process, or be responsible for implementing those } \\
\text { actions. Different groups of stakeholders will need to be involved in different ways in } \\
\text { specific stages of planning. }\end{array}$ \\
\hline $\begin{array}{l}\text { 3, Describing the context for } \\
\text { conservation areas }\end{array}$ & $\begin{array}{l}\text { The planning team describes the social, economic \& political setting for conservation } \\
\text { planning, identifying the types of threats to natural features that can be mitigated by } \\
\text { spatial planning \& the broad constraints on, \& opportunities for, conservation actions }\end{array}$ \\
\hline 4, Identifying conservation goals & $\begin{array}{l}\text { May begin with agreement on a broad vision statement for the region that is then } \\
\text { progressively refined into qualitative goals about biodiversity (e.g. representation, } \\
\text { persistence), ecosystem services, livelihoods \& other concerns. Goals help to identify } \\
\text { the need for spatial data. }\end{array}$ \\
\hline $\begin{array}{l}\text { 5, Collecting data on socio-economic } \\
\text { variables \& threats }\end{array}$ & $\begin{array}{l}\text { Relevant spatially explicit data will include variables such as tenure, extractive uses, } \\
\text { costs of conservation, \& constraints \& opportunities to which planners can respond. } \\
\text { Will also involve predictions about the expansion of threatening processes. }\end{array}$ \\
\hline $\begin{array}{l}\text { 6, Collecting data on biodiversity } \\
\text { \& other natural features }\end{array}$ & $\begin{array}{l}\text { The planning team will collect spatially explicit data on biodiversity that include } \\
\text { representation units (e.g. vegetation types), focal species \& ecological processes. This } \\
\text { may extend to ecosystem services (e.g. maintenance of water flows, carbon } \\
\text { sequestration). }\end{array}$ \\
\hline 7, Setting conservation objectives & $\begin{array}{l}\text { Involves interpreting goals to define quantitative conservation objectives for each } \\
\text { spatial feature (e.g. } 2,000 \text { ha of vegetation type } 16,500 \text { individuals of each species) \&, } \\
\text { where necessary, qualitative objectives related to configuration, past disturbance \& } \\
\text { other criteria. }\end{array}$ \\
\hline $\begin{array}{l}\text { 8, Reviewing current achievement } \\
\text { of objectives }\end{array}$ & $\begin{array}{l}\text { Remote data, \& perhaps also field surveys, are used in this stage to estimate the extent } \\
\text { to which objectives have already been achieved in areas considered to be adequately } \\
\text { managed for conservation }\end{array}$ \\
\hline $\begin{array}{l}\text { 9, Selecting additional conservation } \\
\text { areas }\end{array}$ & $\begin{array}{l}\text { With stakeholders, this stage requires decisions about the location \& configuration } \\
\text { of additional conservation areas that complement the existing ones in achieving } \\
\text { objectives. Factors influencing decisions will include costs, constraints on, \& } \\
\text { opportunities for, effective conservation. }\end{array}$ \\
\hline $\begin{array}{l}\text { 10, Applying conservation actions } \\
\text { to selected areas }\end{array}$ & $\begin{array}{l}\text { Application of conservation actions requires a variety of technical analyses \& } \\
\text { institutional arrangements to ensure that selected areas are given the most feasible \& } \\
\text { appropriate conservation management \& that areas are prioritized for action when } \\
\text { resources are limited }\end{array}$ \\
\hline $\begin{array}{l}\text { 11, Maintaining \& monitoring } \\
\text { conservation areas }\end{array}$ & $\begin{array}{l}\text { Activities ensure that individual areas are managed to promote the long-term } \\
\text { persistence of the values for which they were established. This involves explicit } \\
\text { management objectives \& monitoring to ensure that management actions are effective. }\end{array}$ \\
\hline
\end{tabular}

region (Didier et al., 2009). At the level of strategic (nonspatial) planning there are close links between the Open Standards (Conservation Measures Partnership, 2007) and the WWF Program Standards framework for planning (Morrison et al., 2009).

Our assessment has limitations. We can offer impartiality but, with our particular backgrounds influencing our expectations, we cannot claim objectivity. Also, the four NGOs were not asked to structure their articles according to the stages with which we assess them here. More importantly, the sum of knowledge and experience and the full details of a planning approach cannot be captured in any single article. A comprehensive characterization and comparison of the four approaches would be based on training documents, workbooks, journal articles and case studies, followed by interviews with practitioners and designers. Although we have covered some of these additional sources in developing the IUCN guidelines, we aim here for consistency by limiting our interpretations mainly to the information in the four articles. The numbered headings below correspond to the stages of the planning process (Table 1, Fig. 2).

\section{(1) Scoping and costing the planning process}

At the inception of the planning process the initial boundaries of the planning domain are identified, although later work, for example on identifying stakeholders and collecting data on biodiversity and threats, may lead to boundaries being revised. Decisions are also necessary about 
TABLE 2 Kinds of biodiversity data and objectives described (large squares) by Henson et al. (2009, AWF), Green et al. (2009, TNC), Didier et al. (2009, WCS) and Morrison et al. (2009, WWF). See Bottrill et al. (2006) for a more comprehensive comparison.

\begin{tabular}{|c|c|c|c|c|}
\hline & AWF & TNC & WCS & WWF \\
\hline \multicolumn{5}{|l|}{ Biodiversity data } \\
\hline Representation units $^{1}$ & $\mathbf{\square}$ & $\boldsymbol{\square}$ & $\square^{2}$ & $\square$ \\
\hline Special elements ${ }^{3}$ &.$^{4}$ & $\mathbf{\square}$ & $\square^{5}$ & $\mathbf{\square}$ \\
\hline Focal species ${ }^{6}$ & $\square$ & .7 & $\mathbf{\square}$ & $\overline{\mathbf{a}}$ \\
\hline Biodiversity processes ${ }^{8}$ & $\mathbf{\square}$ & $\boldsymbol{\square}$ & $\square^{9}$ & $\mathbf{\square}$ \\
\hline Objectives & & & & \\
\hline Quantitative $^{10}$ &.$^{11}$ & $\square$ & $\boldsymbol{\square}$ & $\mathbf{a}$ \\
\hline Qualitative $^{12}$ & & $\square$ &.$^{13}$ & \\
\hline
\end{tabular}

${ }^{1}$ Refers to mapped polygons (e.g. vegetation types, marine habitats, abiotic environments) intended to serve as broad surrogates for the distribution of poorly sampled or undescribed species (Noss, 2004)

${ }^{2}$ Not currently part of this approach

${ }^{3}$ Refers to a wide variety of relatively localized features, including species locality records, restricted habitats, breeding or roosting sites and spawning aggregations (Noss, 2004)

${ }^{4}$ Acknowledged as an area for improvement

${ }^{5}$ No example given but special elements have been included in previous applications of the Landscape Species Approach (K. Didier, pers. comm.) ${ }^{6}$ Usually space-demanding animals whose requirements for design criteria such as area, connectivity, neighbouring land uses, and complementary habitats inform decisions about the configuration of systems of conservation areas (Noss, 2004)

${ }^{7}$ No data or objectives on focal species, although these can be incorporated into the methods described for this case study

${ }^{8}$ Surrogates for biodiversity processes (Pressey, 2004) include generic design criteria such as compactness or environmental gradients related to climate change and features associated with specific processes, such as drought refugia, which promote persistence of species and soil interfaces associated with diversification of plant taxa. Strictly speaking, the persistence of focal species involves many processes. Processes are also embedded in definitions of representation units and special elements

${ }^{9}$ Some aspects of processes are embedded in estimates of densities of focal species and responses to threats, e.g. seasonal movements, patchy resources, refugia

${ }^{10}$ Specify the extent or number of biodiversity features to be represented in conservation areas

${ }^{11}$ Not used

${ }^{12}$ Non-quantitative statements (e.g. increased population size) or preferences (e.g. where possible, make conservation areas large and compact)

${ }^{13}$ Have been used with this approach (e.g. connectivity, past disturbance; $\mathrm{K}$. Didier, pers. comm.) and are likely to be used further as methods for area selection are developed to include interactive decisions with experts

the size and composition of the planning team and the funds that are available or have to be raised to address subsequent stages adequately.

Green et al. (2009, TNC), Henson et al. (2009, AWF) and Morrison et al. (2009, WWF) described how planning domains were delineated, defining boundaries flexibly with data collected during the projects, as opposed to using predefined maps of regions. Henson et al. (2009, AWF) considered the distributions and requirements of their species of interest, then watersheds and socio-economic criteria. The boundaries of Kimbe Bay were defined similarly but with representation units (see Table 2 for definition) rather than focal species in mind (Green et al., 2009, TNC). The exercises described by Morrison et al. (2009, WWF) were in Global 200 priority ecoregions (Olson \& Dinerstein, 2002) but they delineated landscapes within them using biological, physical and socio-economic criteria, including provincial boundaries in Quang Nam to align with existing planning processes. The Landscape Species Approach is similarly flexible in its delineation and updating of planning boundaries (K. Didier, pers. comm., WCS). Common to all four were: comments on the importance of multidisciplinary planning teams that included or connected with key stakeholders; emphasis on flexibility of approaches to deal with different objectives, amounts of data, and varying opportunities and constraints; and well developed lists of planning tasks for teams to consider when adapting approaches to particular landscapes or seascapes.

\section{(2) Identifying and involving stakeholders}

The early involvement of stakeholders, including governments, affected communities, and experts, has important benefits for the effectiveness of conservation planning. These include: eliciting information on biodiversity and planning opportunities that is not held in databases and would otherwise be unavailable; understanding the concerns and requirements of people likely to be affected by conservation actions; engendering trust and credibility among key players; engaging with people who may facilitate conservation actions financially and politically; and gaining the support of organizations responsible for implementing conservation actions and maintaining conservation areas into the future (Pierce et al., 2005). All four NGOs strongly emphasized the importance of involving stakeholders, with methods ranging from informal discussions to scientific workshops, community workshops and embedding key stakeholders in planning teams.

Perhaps the best developed strategy for stakeholder engagement is described by Henson et al. (2009, AWF). The Heartland Conservation Process requires significant investment in identifying and engaging stakeholders, including government agencies, local communities, the private sector, other NGOs and research groups. This seems to reflect the 45-year field experience of AWF, with c. 20 years in the Kilimanjaro Heartland. A presence in Kimbe Bay since 1993 has also given TNC insights into the needs of stakeholders. Green et al. (2009, TNC) described a planning process that involved government representatives, a local NGO, and various experts at different stages, including workshops with different purposes and participants. They listed several constraints on working with all stakeholders in the seascape and outlined partial solutions.

Morrison et al. (2009, WWF) described several strategies for involving affected and influential stakeholders, directed at acceptance and implementation of outcomes. For the TransFly, they commented that years of dialogue were needed 
TAвLE 3 Summary of convergence (shaded) and contrast (unshaded) between Didier et al. (2009, WCS), Green et al. (2009, TNC), Henson et al. (2009, AWF), and Morrison et al. (2009, WWF) in the 11 main stages of conservation planning (Table 1, Fig. 2).

Stage of planning process
$\begin{aligned} & \text { 1, Scoping \& costing the planning } \\ & \text { process }\end{aligned}$
process

2, Identifying \& involving stakeholders

3, Describing the context for conservation areas

4, Identifying conservation goals

5, Collecting data on socio-economic variables \& threats

6 , Collecting data on biodiversity \& other natural features

7, Setting conservation objectives

8, Reviewing current achievement of objectives

9, Selecting additional conservation areas

10, Applying conservation actions to selected areas

11, Maintaining \& monitoring conservation areas

\section{Comments}

The main similarity is the flexibility with which landscapes and seascapes were defined, with data collected during the projects, as opposed to using predefined maps of planning domains. Even the criteria used to define their boundaries were similar. The use by WWF of provincial boundaries in Quang Nam (Morrison et al., 2009) was at one end of this spectrum of criteria but evidently effective.

Emphasis on active involvement of stakeholders throughout the planning process was an area of strong agreement, albeit with different methods. The best described process of engagement was that of AWF (Henson et al., 2009), probably reflecting the Foundation's long experience in planning with local communities \& government authorities in the Kilimanjaro landscape.

TNC \& AWF (Green et al., 2009; Henson et al., 2009) described their assessments of both ultimate \& proximate threats \& identified non-spatial actions to complement conservation planning. There were differences in emphasis between organizations but, considering references to supporting information from WCS \& WWF, general agreement on the importance of contextual analyses.

AWF \& WWF (Henson et al., 2009; Morrison et al., 2009) were explicit about goals for biodiversity persistence as well as human livelihoods. In light of supporting guidelines from the four NGOs \& implicit goals by WCS \& TNC (Didier et al., 2009; Green et al., 2009), there was nothing about goals that strongly distinguished the four approaches. TNC, AWF \& WWF (Green et al., 2009; Henson et al., 2009; Morrison et al., 2009) described similar mixes of methods for mapping threats, constraints \& opportunities. The approach by WCS (Didier et al., 2009) is distinctive in dealing with multiple threats by mapping their intensities \& impacts. None directly addressed conservation costs, despite their recognized importance (Naidoo et al., 2006).

There was a spectrum of variation. At one end was WWF (Morrison et al., 2009), using all four kinds of data (Table 2). At the other end was WCS (Didier et al., 2009), dealing only with focal species. For the Kilimanjaro landscape, AWF (Henson et al., 2009) collected data on the size, condition \& landscape context of features.

Objectives ranged from solely quantitative to solely qualitative (Table 2). AWF

(Henson et al., 2009) was familiar enough with one of its landscapes to set objectives in terms of condition \& composition. WCS (Didier et al., 2009) had sufficient data on its focal species to set population targets relative to the impacts of past \& future threats. Methods separated the four NGOs only superficially, with AWF \& WWF explicitly considering existing protected areas (Henson et al., 2009; Morrison et al., 2009), TNC atypically not considering them because of their particular characteristics (Green et al., 2009), \& WCS with clear potential to incorporate them (Didier et al., 2009).

Most differences were minor \& apparently diminishing. The use of planning software with biodiversity experts \& other stakeholders is either established, beginning or anticipated. Planning by AWF (Henson et al., 2009) was, however, distinctive in allocating different conservation actions to particular areas in the selection stage. There were differences of emphasis on particular tasks but all the NGOs pointed to real conservation gains from their planning. AWF (Henson et al., 2009) described the most explicit \& well established method for scheduling. TNC (Green et al., 2009) was explicit about the extended process of negotiating conservation actions within their areas of interest.

Maintenance \& monitoring are core parts of the approach described by AWF (Henson et al., 2009) but are acknowledged as important in guidelines produced by all four NGOs. before planning could begin and that extensive preparatory discussions were also needed in Quang Nam and the Terai. Among the benefits of stakeholder involvement described by Didier et al. (2009, WCS) were understanding and acceptance of conservation action among communities, improvements in land-use planning and conservation policy, and increased funding for research into landscape species.

\section{(3) Describing the context for conservation areas}

This stage sets the scene for all the tasks that follow. Its importance lies mainly in understanding the social, economic and cultural conditions in the planning region and how these shape constraints or opportunities for conservation. Part of this context is an understanding of which threats 
can be addressed spatially, through conservation actions in particular areas, and which require complementary nonspatial actions (examples below). All of these issues are addressed by WCS in its broader approach (Table 1 of Didier et al., 2009) and by the strategic (vs spatial) planning of WWF (Morrison et al., 2009), although are not covered in detail by these articles.

Henson et al. (2009, AWF) identified both proximate and ultimate threats. Among the ultimate threats to biodiversity in the Congo Heartland were inadequate agricultural policy, lack of market access and weak governance. To complement their suite of localized management tools, their non-spatial actions involved developing capacity and leadership for conservation and engaging with partner governments to improve policy and legislation. For Kimbe Bay, the socio-economic appraisal of Green et al. (2009, TNC) included present and likely future human populations, reliance on marine resources for cash and subsistence, and external pressures on marine resources. To complement locally managed marine areas, TNC will be involved in development planning of catchments, promoting sustainable harvest of marine resources and financing conservation-friendly enterprises.

\section{(4) Identifying conservation goals}

As we define them (Table 1), goals are broad qualitative statements that provide a bridge between the values and beliefs upon which conservation efforts are based and the more specific, often quantitative, objectives used in systematic conservation planning. The very generality of goals can help to promote agreement among stakeholders, perhaps beginning with a vision statement for the planning region. An important purpose of goals is also to focus planning teams on the kinds of spatially explicit data that will be required (Stages 5 and 6 ).

Henson et al. (2009) made it clear that underpinning goals for AWF were to improve livelihoods while also promoting the persistence of biodiversity. A similar mix of goals guided WWF's activities in the Terai (Morrison et al., 2009). Elsewhere, WWF has strongly emphasized the importance of vision statements and goals (Dinerstein et al., 2000). Visions and goals are important aspects of the larger approaches of both TNC (The Nature Conservancy, 2007) and WCS (Table 1 of Didier et al., 2009).

\section{(5) Collecting data on socio-economic} variables and threats

By this stage context and goals will have clarified the need for spatially explicit data on socio-economic variables that will influence decisions about specific actions and areas and potentially make conservation decisions more effective. These variables include previous and existing conservation efforts, the costs of conservation (e.g. acquisition and management costs, opportunity costs to users of natural resources; Naidoo et al., 2006), threats to biodiversity and other natural values, and constraints on, and opportunities for, conservation action.

All four NGOs discussed spatially explicit data on at least one of these considerations. Henson et al. (2009, AWF) used projections of future human numbers and activities in the Congo Heartland to identify potential conflicts with the persistence of biodiversity, then designed interventions to address these. Their responses were informed by knowledge of constraints and opportunities, including community interests and the status of forestry concessions. Green et al. (2009, TNC) commissioned a detailed socio-economic assessment of six communities to understand social and cultural settings and uses of natural resources. Their map of conservation costs reflected a gradient from opportunities (low cost) to constraints (high cost) defined by variables such as existing locally managed marine areas and receptivity to conservation action. Case studies by WWF (Morrison et al., 2009) illustrated several ways of addressing this stage: recognition of previous government planning and cultural areas important to communities in the TransFly; and, in Quang Nam, development of a cost layer based on risk of forest clearance.

Didier et al. (2009) described WCS's sophisticated method of mapping the past and future distributions of multiple threats, including direct human activities and indirect impacts such as pollution and introduced species. Mapping previous threats allows planners to identify which of them can be mitigated and avoids the problem of shifting baselines. Maps of future threats indicate scenarios that can be avoided with conservation interventions. Importantly, the human landscapes of WCS (Didier et al., 2009) are based on spatial variations in the intensities of threats. These data are rarely available (Wilson et al., 2005) but valuable. They identify spatial patterns of species-specific impacts, address the elusive problem of combining the impacts of multiple threats, and allow planners to see where conservation actions can have most effect.

\section{(6) Collecting data on biodiversity and} other natural features

Spatially explicit data on biodiversity have been fundamental to systematic conservation planning since its earliest application (Kirkpatrick, 1983), playing a vital, often dominant, role in shaping recommendations for investments. A characteristic of systematic conservation planning is its applicability to different kinds and amounts of data, making it relevant to virtually any terrestrial region and many marine regions. Henson et al. (2009, AWF) and Morrison et al. (2009, WWF) commented on the adaptability of their approaches to different data. The Landscape Species 
Approach is also applicable to lesser-known regions and species (Didier et al., 2009, WCS), and Conservation Action Planning applies to diverse data sources (TNC, 2007).

Notwithstanding this flexibility, the four NGOs, and the approaches they employ, use biodiversity data in different ways (see Table 2 for definitions of data types). Focal species are the primary concern of WCS (Didier et al., 2009) and a major concern of AWF (Henson et al., 2009). Didier et al. (2009, WCS) described the selection of focal species using special-purpose software with the involvement of local stakeholders and scientific experts. Their method of mapping potential densities of these species, adjusted to account for threats, sets a high standard.

Henson et al. (2009, AWF) added other kinds of features to their lists of focal species, including representation units and processes such as flow regimes and migration routes, and collected data on the size, condition and landscape context of each feature. Green et al. (2009, TNC) identified shortage of data as one of the biggest challenges for planning in their remote region. With experts, they identified data of three types as the minimum needed in Kimbe Bay: representation units, special elements, and processes related to connectivity (for which they commissioned a hydrodynamic model) and climate change. The case studies by WWF (Morrison et al., 2009) covered the widest range of features, emphasizing focal species in the Terai but including other types in different combinations elsewhere. These studies required substantial investments in choosing and collecting data. Some of the background work on focal species in the Terai has been published separately (Wikramanayake et al., 2004).

\section{(7) Setting conservation objectives}

A hallmark of systematic conservation planning is its use of explicit conservation objectives, representing the interpretation of goals through the filter of available data. Objectives, especially quantitative ones (e.g. the extent of each representation unit or the number of occurrences of each special element), necessitate discussion about outcomes for biodiversity, limit the potential for expedient, residual conservation decisions, and encourage accountability (Margules \& Pressey, 2000). Quantitative objectives allow the full potential of decision-support software to be realized (Sarkar et al., 2006). Qualitative objectives are, however, almost always needed because of our inability to assign numerical parameters to all aspects of biodiversity pattern and process (e.g. shape, connectivity and species composition related to past extractive uses). Qualitative objectives are typically expressed as characteristics to be maximized, minimized or preferred (e.g. Table 2 in Green et al., 2009, TNC). One of their disadvantages is that their achievement is, by definition, open to personal judgement, limiting repeatability and accountability.
Four main points about objectives emerge from our reading of the NGO articles (Table 2). Firstly, the NGOs used different mixes of quantitative and qualitative objectives. The approach of Henson et al. (2009, AWF) was distinctive in using only qualitative objectives. Green et al. (2009, TNC) developed a comprehensive list of quantitative and, mostly, qualitative objectives, addressing biodiversity pattern and process and socio-economic criteria. The case studies of Morrison et al. (2009, WWF) variously used qualitative and/or quantitative objectives. Didier et al. (2009, WCS) used solely quantitative objectives.

Secondly, some of the objectives for the Kilimanjaro landscape (Henson et al., 2009, AWF) are unusual in addressing the condition and composition of representation units. Achieving these kinds of objectives requires close familiarity with all parts of the landscape, a distinctive aspect of the work there by AWF. Thirdly, and also unusually, three of the NGOs described objectives for restoration. These were framed in different ways but included condition, composition, water flows, connectivity and the extent and density of animals (Didier et al., 2009, WCS; Henson et al., 2009, AWF; Morrison et al., 2009, WWF). Fourthly, the Landscape Species Approach (Didier et al., 2009, WCS), with its attention to just a few relatively well known species, involves unusually well-founded and informative objectives. The combination of mapping threats and estimating densities allows population sizes to be expressed as recovery targets (achieved by reducing mitigatable current threats) and prevention targets (achieved by reducing future threats). Didier et al. (2009, WCS) also emphasized the importance of revising objectives when new information becomes available and, in some cases, of proactive research to obtain this information.

\section{(8) Reviewing current achievement of objectives}

In few landscapes or seascapes will planners work with a blank slate, devoid of conservation actions or previous attempts to identify priorities. In many cases there will be sufficient cultural or legal backing for existing conservation areas to lock them into the architecture of the new plan (Margules \& Pressey, 2000). In other cases, some established conservation areas may be regarded as preferences, not commitments (e.g. non-statutory reserves; Cowling et al., 2003). Existing conservation areas will often contribute to the achievement of objectives. A major purpose of this stage is to review this achievement before selecting new, complementary areas.

An explicit goal of the Heartland Conservation Process is to link, augment and strengthen protected areas (Henson et al., 2009, AWF). It is not clear, however, how the contribution of existing protected areas to exclusively qualitative objectives is assessed. Morrison et al. (2009, WWF) also explicitly considered existing protected areas. A goal of their 
planning in the Vogelkop was to identify unrepresented habitats, although apparently without quantitative objectives. They did, however, measure prior achievement of quantitative objectives for the TransFly. Although TNC's planning typically builds on existing conservation areas, Green et al. (2009) described some local circumstances for which they varied this approach. They did not lock in established areas because this would have led to overrepresentation of some habitats, including some examples in poor condition. Instead they used existing conservation areas to reflect conservation opportunities (Stage 5). For WCS Didier et al. (2009) illustrated how objectives can be matched against the current status of species. Their biological landscapes account for current and potential human activities, so the method is well suited to assessing shortfalls in restoration and prevention objectives.

\section{(9) Selecting additional conservation areas}

Selecting additional conservation areas is what many people would associate with the term conservation planning. Three points are most relevant in this context. Firstly, no matter how carefully and inclusively new conservation areas are identified, changes to these areas will usually be necessary before conservation actions are applied (in Stage 10). Some areas, for example, will be unexpectedly lost and some data on vegetation types and species localities will inevitably prove to be wrong. Secondly, because many factors that determine which conservation actions are eventually applied to specific areas cannot usually be predicted accurately across whole landscapes or seascapes, this stage usually identifies generic conservation areas, not spatially explicit combinations of particular actions. Thirdly, selection often has two aspects: analysis with decision-support systems to map the options for achieving objectives, and judgement by experts and other stakeholders to resolve these options drawing on knowledge not captured in data sets. Ideally, both aspects together will help planners balance objectives for biodiversity with the aspirations of people.

The four NGOs illustrated these points in different ways. TNC and AWF explicitly recognized the preliminary nature of conservation plans. Green et al. (2009, TNC) identified areas of interest within which locally managed marine areas would be negotiated with communities, with selection of areas intended to facilitate this process. For the Congo Heartland, Henson et al. (2009, AWF) indicated that their initial planning would be reviewed by species experts. Their work is unusual in allocating different kinds of conservation management to different areas. For Kilimanjaro, the ability to zone in this stage probably reflects AWF's long presence there and its close familiarity with the feasibility and effectiveness of alternative actions.

The four NGOs selected new areas in different ways. For Kimbe Bay, Green et al. (2009, TNC) used Marxan software
(Possingham et al., 2006) and resolved options in a workshop, with adjustments to ensure that all objectives, some of which were qualitative and outside the software's objective function, were achieved. Area selection in case studies by WWF (Morrison et al., 2009) varied from solely expertbased (Vogelkop) to combining software with experts and key stakeholders (TransFly and Quang Nam). For the Terai, spatial analysis relied on a cost-distance model to identify core areas and corridors for tigers. Selection of areas by AWF (Henson et al., 2009) relied on participatory planning meetings, stakeholder consultation, and internal deliberations by the project team. Some additional explicitness for the Congo Heartland was provided by intersecting suitability for wildlife with suitability for expanding human activities. Didier et al. (2009, WCS) indicated that prioritizing areas for action is in development, although they anticipated the use of software to plan for multiple species and acknowledged the importance of expert stakeholders in the selection process.

\section{(10) Applying conservation actions to selected areas}

Notwithstanding the increasing effectiveness of systematic conservation planning in shaping real decisions (Pressey et al., 2009), the process has often lacked continuity of information and personnel between Stage 9 and this stage (Pierce et al., 2005). There are two important consequences. Firstly, some aspects of applying conservation actions have not had the attention they deserve. These include: managing changes to selected areas and preferred actions imposed by unexpected constraints on conservation actions, scheduling incremental conservation actions within the limits of annual budgets, and mainstreaming plans into the activities of organizations responsible for planning and development. The second consequence is that much careful and expensive planning has failed to achieve its potential outcomes. An important aspect of the four NGO articles is that they depart from these generalizations about past planning by describing the transition from selection to application or outlining ways of facilitating it.

Henson et al. (2009, AWF) described a highly developed approach to implementing actions. AWF commits to a longterm field presence in each of its landscapes, with a planning horizon of 10-15 years. Having developed a zoning plan, AWF schedules conservation actions and adjusts them according to their monitored effects on biodiversity and livelihoods. This has achieved real protection, described for the Kilimanjaro landscape.

TNC is proceeding with a structured process of negotiating actions with communities in Kimbe Bay. This is expected to take some years, which is typical of activities in Stage 10, but Green et al. (2009, TNC) noted that negotiations were completed or underway to apply actions in eight near-shore areas of interest. Mainstreaming here will 
highlight priority areas in 5-year provincial development plans. Case studies from WWF (Morrison et al., 2009) demonstrated several approaches to applying actions: scheduling and applications of conservation action in the Vogelkop, endorsement and adoption of conservation areas in Quang Nam by provincial authorities and, in the Terai, mainstreaming and guidance for community forestry projects with observable benefits for focal species.

The Landscape Species Approach's (Didier et al., 2009, WCS) consideration of multiple, spatially explicit threats facilitates tailored actions in particular places. These authors also demonstrated that mainstreaming can begin before the selection of areas in Stage 9. Their approach, even without identifying priority areas, has introduced biodiversity and conservation concerns into land use and development planning in several regions.

\section{(11) Maintaining and monitoring conservation areas}

Stage 11 concerns ongoing management of conservation areas. Its main purpose is to ensure that the values for which conservation areas have been established are maintained. This requires each area to be placed in its landscape or seascape context so that its particular contributions to objectives can be identified. Management then proceeds with a similar set of stages to the whole planning process but focused on individual areas (Margules \& Pressey, 2000), with objectives identified, zoning and management activities allocated, and their effectiveness monitored, with adjustment as required. Because they concentrate on spatial analyses none of the four NGO articles place much emphasis on this stage. Green et al. (2009, TNC) acknowledged the need for monitoring to measure the effectiveness of conservation actions as part of the community-based management process. Henson et al. (2009, AWF) described monitoring and adaptation as an established, core part of their Heartland Conservation Process. Guidelines for this stage have been developed by TNC (2007), WWF (Loucks et al., 2004) and WCS (Didier et al., 2009, Table 1).

\section{Summary of convergence and contrasts}

Table 3 summarizes our interpretations. In Stages 1-4 there are similarities between the approaches and general agreement on the importance of key tasks. Contrasts are more apparent in ways of collecting data and identifying objectives (Stages $5-7$ ). The four approaches converge again in the stages (8-11) concerned with spatial assessment, application of actions, and ongoing management. In stages dominated by convergence, differences in specific methods reflect either real differences in emphasis or incidental divergence related to limitations of data or other projectspecific constraints. In stages dominated by contrasts, the differences tend to reflect deliberate methodological deci- sions. Even here, though, there is considerable complementarity between approaches and strong potential to combine elements of each.

\section{Challenges}

Approaches to systematic conservation planning by governments, NGOs and research groups are becoming increasingly sophisticated and influential but have shortcomings, both perceived (Smith et al., 2006) and real (Sarkar et al., 2006). One recognized challenge is the need to promote better the persistence of the processes that generate and maintain biodiversity (Pressey et al., 2007). These include population dynamics related to connectivity, patch dynamics of disturbance and resources, adjustment of distributions to climate change and diversification of lineages. Another acknowledged challenge is the need for more extensive and effective implementation of conservation actions, requiring the involvement of diverse stakeholders and tactical decisions that address the dynamics of anthropogenic threats (Pierce et al., 2005). Of the many other potential improvements we discuss here only two that are common to the four NGO approaches and should be addressed by planners everywhere.

\section{Managing the transition from planning to applying conservation actions}

Applying conservation actions to selected areas (Stage 10) is typically incremental and protracted. To remain relevant plans developed in Stage 9 must therefore be managed as dynamic pictures of conservation interests that reflect many kinds of changes. These include: adjustments of the boundaries of notional planning units such as grids to accommodate actual units of management (e.g. Green et al., 2009, TNC); unanticipated loss of areas of interest; unexpected commitments to areas not previously selected; new data on biodiversity, costs and threats; and lack of interest among local communities in conservation management. These and other changes require the configuration of an initial plan to be adjusted regularly by removing some areas and replacing them with others. Day-to-day management of a living conservation plan requires archiving and updating data sets and protocols for reanalysis of data and altering the configuration of the plan, with due consultation among stakeholders. All this relies on longterm institutional commitment and continuity of personnel for which many agencies and NGOs are not prepared. Another aspect of this commitment is the formulation of a long-term strategy, in the face of ongoing attrition of biodiversity, for scheduling incremental investments to minimize the extent to which objectives are compromised before they can be achieved. When many areas of interest are both highly threatened and highly valuable for diverse objectives, 
choices about which areas to protect are also choices about which areas and objectives will be lost (Pressey et al., 2007). Explicit guidelines for making these choices have yet to be developed.

\section{Assessing the costs and benefits of conservation planning}

Beyond the costs of conservation actions (Naidoo et al., 2006), planning itself is expensive. Although the costs of planning are rarely declared, two of the NGO articles reported costs. TNC's planning in Kimbe Bay cost an estimated USD 400,000 (Green et al., 2009), including scientific research (54\%), staff time (35\%) and workshops (10\%). Didier et al. (2009, WCS) estimated, across eight landscapes, that their entire approach took an average of $c$. one person-year per landscape, of which c. $60 \%$ was spent on the spatially explicit steps described. Based on these figures $c$. USD 1 million per landscape or seascape may not be an unreasonable estimate given: (1) the desirability of planning with comprehensive data sets that combine the focal species of Didier et al. (2009, WCS) and the data types used by other NGO approaches, (2) the frequent need for extensive consultation and preparation before the planning process begins (Henson et al., 2009, AWF; Morrison et al., 2009, WWF), and (3) the need for extensive subsequent work to manage the dynamics of plans and to overhaul them periodically. Planning, when extended across the many thousands of landscapes and seascapes where it is needed, therefore represents a large financial commitment by agencies and NGOs, even if training (Didier et al., 2009, WCS) and accumulation of expertise provide economies of scale.

Notwithstanding the increasing application of systematic conservation plans, the benefits of these large investments have not been compellingly demonstrated with empirical data. One need is to explain the consequences of not planning, either by failing to invest in conservation actions or investing in the wrong places, at the wrong times, in the wrong ways. Convincing arguments will need to be based on projections of alternative futures with and without planning. Another need is to measure the multiple potential benefits of planning that are understated in assessments of the so-called implementation crisis (Knight et al., 2006). These include: (1) direct and sometimes extensive influence on implementation of conservation actions, exemplified by Green et al. (2009, TNC), Henson et al. (2009, AWF) and Morrison et al. (2009, WWF), (2) indirect influence on conservation actions without actual implementation, either by shaping of land-use and development plans (Didier et al., 2009, WCS) or avoidance by developers and resource users of areas of interest to NGOs, (3) raising of expectations among diverse stakeholders about the proportions of regions needed to achieve conservation objectives (Svancara et al., 2005), (4) influence of systematic planning principles on policy and legislation (Driver et al., 2005), and (5) progressive improvement of conservation plans by learning from previous exercises (Conservation Measures Partnership, 2007). Direct implementation, whilst desirable, is not the only means by which the benefits of conservation planning can be realized. Successful outcomes are not necessarily well predicted by direct implementation, and can be measured to shed additional light on the effectiveness of planning (Kapos et al., 2009).

\section{Acknowledgements}

We thank the partners of the USAID Global Conservation Program for the opportunity to contribute this article. We are grateful to Holly Dublin, previous Chair of the IUCN's Species Survival Commission, and Nik Lopoukhine, Chair of IUCN's World Commission for Protected Areas, who initiated and continue to support our guidelines project that produced the 11-stage framework used here. Comments on the draft manuscript came from representatives of USAID, the African Wildlife Foundation, The Nature Conservancy, the Wildlife Conservation Society, WWF and two other reviewers.

\section{References}

Bottrill, M., Didier, K., Baumgartner, J., Boyd, C., Loucks, C., Oglethorpe, J. et al. (2006) Selecting Conservation Targets for Landscape-scale Priority Setting: A Comparative Assessment of Selection Processes Used by Five Conservation NGOs for a Landscape in Samburu, Kenya. World Wildlife Fund, Washington, DC, USA.

Brooks, T., da Fonseca, G.A.B. \& Rodrigues, A.S.L. (2004) Species, data, and conservation planning. Conservation Biology, $18,1682-1688$.

Calabrese, J.M. \& Fagan, W.F. (2004) A comparison-shopper's guide to connectivity metrics. Frontiers in Ecology and the Environment, 2, 529-536.

Conservation Measures Partnership (2007) Open Standards for the Practice of Conservation, v. 2.o. Http://conservationmeasures.org/ CMP/Site_Docs/CMP_Open_Standards_Version_2.o.pdf [accessed 8 June 2009].

Cowling, R.M. \& PRESSEY, R.L. (2003) Introduction to systematic conservation planning in the Cape Floristic Region. Biological Conservation, 112, 1-13.

Cowling, R.M., Pressey, R.L., Rouget, M. \& Lombard, A.T. (2003) A conservation plan for a global biodiversity hotspot-the Cape Floristic Region, South Africa. Biological Conservation, 112, 191-216.

Didier, K.A., Glennon, M.J., Novaro, A., Sanderson, E.W., Strindberg, S., Walker, S. \& Di Martino, S. (2009) The Landscape Species Approach: spatially-explicit conservation planning applied in the Adirondacks, USA, and San GuillermoLaguna Brava, Argentina, landscapes. Oryx, 43, 476-487.

Dinerstein, E., Powell, G., Olson, D., Wikramanayake, E., A веll, R., Loucks, C. et al. (200o) A Workbook for Conducting Biological Assessments and Developing Biodiversity Visions for Ecoregion-based Conservation. Part 1: Terrestrial Ecoregions. WWF, Washington, DC, USA.

Driver, A., Maze, K., Rouget, M., Lombard, A.T., Nel, J., Turpie, J.K. et al. (2005) National Spatial Biodiversity Assessment 
2004: Priorities for Biodiversity Conservation in South Africa. South African National Biodiversity Institute, Pretoria, South Africa.

Gordon, E.A., Franco, O.E. \& Tyrrell, M.L. (2005) Protecting Biodiversity: A Guide to Criteria used by Global Conservation Organizations. Yale School of Forestry and Environmental Studies, New Haven, USA.

Green, A., Smith, S.E., Lipsett-Moore, G., Groves, C., Peterson, N., Sheppard, S. et al. (2009) Designing a resilient network of marine protected areas for Kimbe Bay, Papua New Guinea. Oryx, 43, 488-498.

Groves, C.R., Jensen, D.B., Valutis, L.L., Redford, K.H., Shaffer, M.L., Scott, J.M. et al. (2002) Planning for biodiversity conservation: putting conservation science into practice. BioScience, 52, 499-512.

Henson, A., Williams, D., Dupain, J., Gichohi, H. \& Muruthi, P. (2009) African Wildlife Foundation's Heartland Conservation Process: enhancing biodiversity conservation and livelihoods through landscape-scale conservation planning in Africa. Oryx, $43,508-519$.

Johnson, N. (1995) Biodiversity in the Balance: Approaches to Setting Geographic Conservation Priorities. Biodiversity Support Program, Washington, DC, USA.

Kapos, V., Balmford, A., Aveling, R., Bubb, P., Carey, P., Entwistle, A. et al. (2009) Outcomes, not implementation, predict conservation success. Oryx, 43, 336-342.

Kirkpatrick, J.B. (1983) An iterative method for establishing priorities for the selection of nature reserves: an example from Tasmania. Biological Conservation, 25, 127-134.

Knight, A.T., Cowling, R.M. \& Campbell, B.M. (2006) An operational model for implementing conservation action. Conservation Biology, 20, 408-419.

Langhammer, P.F., BaKarR, M.I., Bennun, L.A., Brooks, T.M., Clay, R.P., DarWAll, W. et al. (2007) Identification and Gap Analysis of Key Biodiversity Areas: Targets for Comprehensive Protected Area Systems. IUCN, Gland, Switzerland.

Lombard, A.T., Johnson, C.F., Cowling, R.M. \& Pressey, R.L. (2001) Protecting plants from elephants: botanical reserve scenarios within the Addo Elephant National Park, South Africa. Biological Conservation, 102, 191-203.

Loucks, C., Morrison, J., Palminteri, S., Springer, J. \& Strand, H. (2004) From the Vision to the Ground: A Guide to Implementing Ecoregion Conservation in Priority Areas. WWF, Washington, DC, USA.

Margules, C.R. \& Pressey, R.L. (2000) Systematic conservation planning. Nature, 405, 243-253.

Morrison, J., Loucks, C., Long, B. \& Wikramanayake, E. (2009) Landscape-scale spatial planning at WWF: a variety of approaches. Oryx, 43, 499-507.

Naidoo, R., Balmford, A., Ferraro, P.J., Polasky, S., Ricketts, T.H. \& Rouget, M. (2006) Integrating economic costs into conservation planning. Trends in Ecology \& Evolution, $21,681-687$.

Noss, R.F. (2004) Conservation targets and information needs for regional conservation planning. Natural Areas Journal, 24, 223231.

Olson, D.M. \& Dinerstein, E. (2002) The Global 200: priority ecoregions for global conservation. Annals of the Missouri Botanical Garden, 89, 199-224.

Pierce, S.M., Cowling, R.M., Knight, A.T., Lombard, A.T., Rouget, M. \& Wolf, T. (2005) Systematic conservation planning products for land-use planning: interpretation for implementation. Biological Conservation, 125, 441-458.
Possingham, H.P., Wilson, K.A., Andelman, S.J. \& Vynne, C.H. (2006) Protected areas: goals, limitations, and design. In Principles of Conservation Biology (eds M.J. Groom, G.K. Meffe \& C.R. Carroll), pp. 507-533. Sinauer Associates, Sunderland, USA.

PRESSEY, R.L. (2004) Conservation planning and biodiversity: assembling the best data for the job. Conservation Biology, 18, 1677-1681.

Pressey, R.L., Cabeza, M., Watts, M.E., Cowling, R.M. \& Wilson, K.A. (2007) Conservation planning in a changing world. Trends in Ecology \& Evolution, 22, 583-592.

Pressey, R.L., Watts, M.E., Barrett, T.W. \& Ridges, M.J. (2009) The C-Plan conservation planning system: origins, applications, and possible futures. In Spatial Models for Conservation (eds A. Moilanen, H.P. Possingham \& K.A. Wilson), pp. 211-234. Oxford University Press, Oxford, UK.

Redford, K.H., Coppolillo, P., Sanderson, E.W., Da Fonseca, G.A.B., Dinerstein, E., Groves, C. et al. (2003) Mapping the conservation landscape. Conservation Biology, 17, 116-131.

Rodrigues, A.S.L., AкÇakaya, H.R., Andelman, S.J., Bakarr, M.I., Boitani, L., Brooks, T.M. et al. (2004) Global gap analysis: priority regions for expanding the global protected-area network. BioScience, 54, 1092-1100.

Sarkar, S., Pressey, R.L., Faith, D.P., Margules, C.R., Fuller, T., Sтомs, D.M. et al. (2006) Biodiversity conservation planning tools: present status and challenges for the future. Annual Review of Environment and Resources, 31, 123-159.

Smith, R.J., Goodman, P.S. \& Matthews, W.S. (2006) Systematic conservation planning: a review of perceived limitations and an illustration of the benefits, using a case study from Maputaland, South Africa. Oryx, 40, 400-410.

Svancara, L.K., Brannon, R., Scott, J.M., Groves, C.R., Noss, R.F. \& Pressey, R.L. (2005) Policy-driven versus evidence-based conservation: a review of political targets and biological needs. BioScience, 55, 989-995.

The Nature Conservancy (2007) Conservation Action Planning Handbook. The Nature Conservancy, Arlington, USA.

Vane-Wright, R.I., Humphries, C.J. \& Williams, P.H. (1991) What to protect? Systematics and the agony of choice. Biological Conservation, 55, 235-254.

Wikramanayake, E., McKnight, M., Dinerstein, E., Joshi, A., Gurung, B. \& S Mith, D. (2004) Designing a conservation landscape for tigers in human-dominated environments. Conservation Biology, 18, 839-844.

Wilson, K., Pressey, R.L., Newton, A., Burgman, M., Possingham, H. \& Weston, C. (2005) Measuring and incorporating vulnerability into conservation planning. Environmental Management, 35, 527-543.

\section{Biographical sketches}

Вов Pressey leads an interdisciplinary research group focused on conservation planning for sustainable use of natural resources. His influence on practice includes close involvement with the systematic design of c. 1 million ha of reserves in New South Wales, and collaborative projects that have influenced conservation decisions extensively in other countries. He is currently working on projects in the Coral Triangle, China, South Africa, Brazil, Papua New Guinea and Mexico. Madeleine Bottrill's research aims to evaluate biological and social outcomes from conservation projects, with a focus on the Polynesia-Micronesia hotspot. She previously led an IUCN initiative to develop guidelines on conservation planning, convened by the Species Survival Commission and World Commission on Protected Areas. 